\title{
Por máQuinas de guerra EM TEMPOS DE MILITARIZAÇÃO HIGH-TECH
}

\author{
Tania Mara Galli Fonseca \\ Fernanda Spanier Amador ${ }^{\star \star}$
}

\begin{abstract}
Resumo
Este artigo trata de refletir sobre modos de comunicabilidade empreendidos no universo das Novas Tecnologias, procurando ultrapassar os efeitos de uma discursividade já instalada, de que nesta esfera, vida e criação nutrem-se uma a outra. Problematizamos tal concepção pensando a respeito de uma micropolítica na rede tecnológica que se faça por heterogeneidade expressiva, fundamentandonos no pensamento de Gilles Deleuze e Félix Guattari. Trata-se de uma política operada entre guerreiros e soldados high-tech, capaz de introduzir uma espécie de (in) disciplina nas cadeias discursivas que se estabelecem nos ambientes computadorizados, na tentativa de efetivamente constitui-los como locus de produção da diferença.
\end{abstract}

Palavras-chave: Novas Tecnologias (NTICs); Linguagem; Micropolítica.

\section{ON BEHALF OF THE WAR MACHINES IN TIMES OF HIGH TECH MILITARIZATION}

\begin{abstract}
This text relates to communication and ways of communicability involved in the NTCIs world. It tries to surpass the effects of an alreday installed discursivity which states that in this environment life and creation nurture one another. We discuss the concept of micro politics in a technological net which can be done through expressive hetorogenicity, all this text uses a reference of Gilles Deleuze and Félix Guattari. It relates to a politics operated between warriors and hightech soldiers who are able to introduce a type of (in) discipline in the discursive chains established in computer based environments, in an attempt to effectively turn them into a locus of production of difference.
\end{abstract}

Keywords: New Technology (NTCI's); Language; Micro Politics

^Psicóloga, Docente do Programa de Pós-Graduação em Psicologia Social e Institucional / Universidade Federal do Rio Grande do Sul e do Programa de Pós-Graduação em Informática na Educação/UFRGS. Endereço: Universidade Federal do Rio Grande do Sul, Instituto de Psicologia UFRGS, Programa de Pós-Graduação em Psicologia Social e Institucional. Endereço: Rua Ramiro Barcelos, 2600 - Sala 13. Santana. CEP: 90035-003 - Porto Alegre, RS - Brasil.

E-mail: tfonseca@via-rs.net

* Psicóloga, Docente do Departamento de Psicologia da Universidade de Santa Cruz do Sul (UNISC), Doutoranda em Informática na Educação/UFRGS. 
Donna Haraway (2000), em seu "Manifesto Ciborgue...", chama a atenção para o fato de que os elementos fundamentais da tecnologia contemporânea assemelham-se ao símbolo dos militares em suas operações: comando-controle-comunicação-inteligência. Assim, movida pelo interesse de potencializar uma política em tempos informatizados, ela instiga a pensar sobre como as tecnologias podem congelar fluidas interações sociais, constituindo instrumentos para imposição de certa ordem de discurso o que nos leva a pensar sobre a urgência de criação de Máquinas de Guerra (DELEUZE; GUATTARI, 1997) no interior da aparelhagem high-tech, como maneira de resistir aos movimentos de tradução da heterogeneidade expressiva pela codificação digital.

Referimo-nos à criação de guerreiros e não de soldados em tempos de uma Sociedade de Informação - a qual é definida por Castels (2000) como sendo marcada pelo conjunto de tecnologias em microeletrônica, computação e telecomunicações - capazes de introduzir uma espécie de (in) disciplina nas cadeias discursivas que se estabelecem via ambientes computadorizados, na tentativa de efetivamente constituí-los, como espaço de encontro de sons, palavras, ideias que produzam diferença. Guerreiros em uma sociedade globalizada onde conectar-se e comunicar-se, tornaram-se tarefa obrigatória.

Propomo-nos, então, a refletir a respeito dos modos de comunicabilidade empreendidos no universo das Novas Tecnologias de Informação e Comunicação, procurando ultrapassar os efeitos de certa discursividade já instalada - quase que como obviedade - de que nessa esfera, vida e criação nutrem-se uma a outra.

Começamos com o próprio pensamento de Haraway (2000). Seguimos as pistas deixadas pela autora de que no universo tecnológico há uma especial peculiaridade: as fronteiras humanos-máquinas são transgredidas, elemento esse que pode ser explorado como um dos componentes de um necessário trabalho político frente a modos de dominação. A seguir, abordamos o pensamento de Deleuze e Guattari (1995) a respeito da Linguagem por onde exercem uma crítica a seu sistema significante, finalizando com considerações a partir das noções de Aparelho de Estado e de Máquina de Guerra propostas por Deleuze e Guatarri (1997) para pensarmos a respeito de uma micropolítica na rede tecnológica que se faça por heterogeneidade expressiva.

\section{Haveria uma Política dos Ciborgues?}

Haraway (2000) aborda a imagem do ciborgue: um organismo cibernético, híbrido de máquina e organismo, criatura de realidade social e também de ficção. Trata-se de uma experiência que muda aquilo que conta como "experiência feminina" no final do Século XX, aspecto esse central em sua análise, dada sua incursão no campo dos estudos feministas, mas que, contudo, não será foco específico em nosso trabalho. Elegemos, em lugar disso, seus questionamentos a respeito da cultura high-tech, a qual contesta dualismos, o que abre caminho para pensarmos acerca de vias para um trabalho político em tempos informatizados. Uma política que pensamos enquanto estratégia que produz subjetividades convergentes com a defesa da própria vida, apostando na singularidade como 
via para o fortalecimento dos coletivos. Pauta-se num compromisso com a não psicologização do cotidiano e da vida social que produz uma oposição entre os domínios público e privado, situando-se numa perspectiva de que a subjetividade é entendida dentro do contexto dinâmico das produções sociais apostando na capacidade das pessoas de agirem e reagirem, mas também, e sobretudo, de buscarem caminhos diferenciados; de instaurarem formas múltiplas de vida e de ação, movidas por um desejo revolucionário.

Haraway argumenta em favor do ciborgue como uma ficção que mapeia nossa realidade social e corporal e também como recurso imaginativo que pode fazer surgir frutíferos acoplamentos. Para ela, somos ciborgues desde o final do século XX e sermos assim é nossa ontologia, o que determina a nossa política. Diz ela: "O ciborgue é uma imagem condensada tanto da imaginação quanto da realidade material: esses dois centros, conjugados, estruturam qualquer possibilidade de transformação histórica" (HARAWAY, 2000, p. 41).

Assim, chamando a atenção para a confusão de fronteiras operada pelos acoplamentos sociais, corporais, tecnológicos e imaginativos da Era dos Ciborgues, a autora conduz seu pensamento em termos de um trabalho político que se situa em fraturas tais como as das narrativas de origem humanista, tarefa atribuída ao desenvolvimento individual e à história, como o fazem a psicanálise e o marxismo. E ainda, da ideia de unidade original identificada com a natureza, uma vez que, com o ciborgue, a natureza e a cultura reestruturam-se, não podendo mais uma ser o objeto de apropriação ou de incorporação pela outra.

Afirma Haraway (2000, p. 44):

Os ciborgues não são reverentes; eles não conservam qualquer memória do cosmo: por isso, não pensam em recompô-lo. Eles desconfiam de qualquer holismo, mas anseiam por conexão - eles parecem ter uma inclinação natural por uma política de frente unida, mas sem o partido de vanguarda.

Outras fraturas apresentadas por ela referem-se aos limites entre o humano e o animal e entre humanos e máquinas, quando comenta que se tornaram completamente ambíguas as diferença entre o natural e o artificial, entre a mente e o corpo, entre aquilo que se autocria e aquilo que é externamente criado.

Desse modo, destaca que os ciborgues subvertem as totalidades orgânicas, subvertendo também a certeza daquilo que conta como natureza, acarretando um giro epistemológico fundamental, já que a autoria/autoridade transcendente da interpretação vê-se abalada, pois a humanidade, como fundamento último da criação, encontra-se atravessada por elementos provenientes de outra natureza.

Chamando a atenção, ainda, para um outro rompimento operado na Sociedade Tecnológica, o dos limites entre o físico e o não físico, os quais se tornam altamente imprecisos, destaca o abalo que se dá nos planos da representação da divindade e das relações de poder, já que o "pequeno" passa a ser perigoso. Diz ela: 
É precisamente a ubiqüidade e a invisibilidade dos ciborgues que faz com que essas minúsculas e leves máquinas sejam mortais. Eles são, tanto política quanto materialmente - difíceis de ver. Eles têm a ver com a consciência - ou com sua simulação. Eles são significantes flutuantes [...] (HARAWAY, 2000, p. 49).

Contudo, mesmo alertando para os perigos de tais fronteiras transgredidas, destaca suas potencialidades para fazer uma política pelas fissuras identitárias e por abalos nos fundamentalismos. Refletindo sobre o que define como uma Informática da Dominação - aquela instaurada com a mudança da sociedade industrial e orgânica para um sistema polimorfo, informacional em que as velhas dominações hierárquicas são substituídas por aparatos tecnológicos - , fala em uma cidadania do tipo ciborgue em contraposição às noções de público e privado. Desse modo, destaca a necessidade de fontes renovadas de análise e de ação política.

Para ela, as tecnologias ao mesmo tempo em que implicam fluidas interações sociais, também operam como instrumentos para a imposição de significados, conforme evidencia o trecho a seguir:

[...] as ciências da comunicação e as biologias modernas são construídas por uma operação comum - a tradução do mundo em termos de um problema de codificação, isto é, a busca de uma linguagem comum na qual toda a resistência ao controle instrumental desaparece e toda a heterogeneidade pode ser submetida à desmontagem, à remontagem, ao investimento e à troca (HARAWAY, 2000, p. 70).

No rastro dessa reflexão, Haraway chega a afirmar que as Novas Tecnologias de Informação e Comunicação são fundamentais para a erradicação da vida pública facilitando o florescimento de uma instituição militar high-tech permanente e produzindo formas modernas de vida privada, extraindo, dessa mesma situação, os elementos para pensar uma política do ciborgue.

Tal política se faria por uma luta pela linguagem por parte dos seres ciborgueanos. Linguagem essa que recusa um código único pautado na pureza do humano, já que até mesmo essa dimensão, a de humanidade, encontra-se abalada, perturbando por sua vez, matrizes ontológicas e identitárias. E é esse abalo na concepção de humano trazida pelas Novas Tecnologias, que guarda, ao nosso ver, uma potência peculiar na reflexão de Haraway para pensarmos em termos de ação política no universo high-tech por remeter a uma zona não pós nem tampouco pré-humana, mas infrahumana, infrapessoal. Uma zona prévia ao Ser caracterizada por hibridicidade.

Assim, a autora salienta o quanto a cultura high-tech contesta os dualismos por não deixar claro quem faz e quem é feito na relação entre o humano e a máquina, destacando que nessa (con)fusão pode-se fazer uma linguagem distinta: herética e heteroglóssica. Uma em que linguagem estaria a serviço da instauração de uma maquinaria e não de uma mecânica comunicativa. 


\section{De Maquinaria Comunicativa na Linguagem e Mecânica INFORMACIONAL}

Deleuze e Guattari (1995) discutem acerca da linguagem destacando suas vinculações com o poder. Para eles, os enunciados enquanto unidades elementares da linguagem, são palavras de ordem: "A linguagem não é mesmo feita para que se acredite nela, mas para obedecer e fazer obedecer" (DELEUZE; GUATTARI, 1995, p.12).

Produzem, desse modo, uma torção fundamental: apontam que a ordem não se relaciona com significações prévias, mais sim o inverso. Com isso, sugerem que um trabalho político pela linguagem faz-se por uma espécie de traição dos significados neles mesmos, levando-os a um trânsito pelo Fora a-significante, pelo infrapessoal o qual por ser regido sob o signo do a-gramático - capaz de tensionar a língua a seus limites - se oferece como possibilidade de subversão de qualquer ordenamento e comando. Trata-se de comunicar signos, não significados.

Deleuze (1988) fala de um Fora que “dentro", consiste em uma matéria móvel das forças, do qual se produz um exterior como meio de agenciamentos concretos no qual se atualizam suas relações. Assim, um investimento político e criativo pela linguagem se cumpriria, então, por estratégias que levassem a vida a se insurgir nela, por uma espécie de mudez ou sussurro perturbantes das lógicas significante e sujeitante.

Apontam eles que a linguagem não é a vida, ela dá ordens a ela, caracterizando-se por ser um discurso indireto que vai sempre de um dizer a um outro dizer. Assim, a linguagem não é estabelecida entre algo visto, sentido ou dito, ela transmite algo que foi comunicado. Não se diz as coisas e sim das coisas; trata-se de transmissão de palavra de ordem e não comunicação de um signo como informação.

Desse modo, há relações intrínsecas entre a fala e determinadas ações que se realizam quando estas palavras são ditas - dimensão performativa; bem como entre a fala e determinadas ações que se realizam quando falamos - aspecto ilocutório. São esses atos, o performativo e o ilocutório, relações imanentes dos enunciados, que foram chamados de pressupostos implícitos e não discursivos.

Por eles, vemo-nos diante da impossibilidade de conceber a linguagem como um código e a fala como comunicação de uma informação, porque ordenar não é informar um comando, mas efetuar esse ato. Trata-se de pragmática, pois é impossível, também, definir uma semântica, uma sintaxe e mesmo uma fonemática, como zonas científicas da linguagem, bem como é igualmente impossível manter uma distinção língua-fala, visto que a fala não pode mais ser definida pela simples utilização individual e extrínseca de uma significação primeira, ou pela aplicação variável de uma sintaxe prévia: ao contrário, são o sentido e a sintaxe da língua que não se deixam definir independentemente dos atos de fala que ela pressupõe. 
Dizem Deleuze e Guatarri (1995, p. 16):

Chamamos palavras de ordem não uma categoria particular de enunciados explícitos (por exemplo, no imperativo) mas a relação de qualquer palavra ou de qualquer enunciado com pressupostos implícitos, ou seja, com atos de fala que se realizam no enunciado, e que podem se realizar apenas nele. As palavras de ordem não remetem então, somente aos comandos, mas a todos os atos que estão ligados aos enunciados por uma "obrigação social".

A chave para pensar uma micropolítica na linguagem, está, então, no argumento de que a relação entre o enunciado e o ato interior, é imanente, sem contudo, guardar identidade. Existe "redundância" entre ato e enunciado, em lugar de identidade, ou seja, fala-se o que se faz e faz-se o que se diz; fala-se da vida (com)formando-a. Assim, uma política da linguagem se faria ao provocar-se uma perturbação entre atos de fala e enunciado; contribuindo, assim, para um abalo nas identidades ao instaurar uma abertura ao signo; uma heresia em relação aos códigos e seus significados.

Abordando o esquema da informática, dizem Deleuze e Guattari (1995) que ele admite, por princípio, uma informação máxima ideal, fazendo da redundância uma simples condição limitativa que diminui este extremo almejado. Contestando tal assertiva, dizem os autores que a informação é apenas a condição mínima para a transmissão das palavras de ordem não existindo jamais (in)formação sem ruídos. Assim sendo, o trabalho da linguagem em relação à informação não se volta para a oposição de tais ruídos e sim às indisciplinas que na linguagem trabalham. Uma indisciplina que sintoniza com (out)formação, ou com o Fora na informação, aspecto esse instigante para pensarmos o universo informacional e os desafios concernentes a uma heterogeneidade comunicativa nessa esfera.

Assim, há uma subordinação da informação e da comunicação, ou, mais ainda, da significância e da subjetivação, em relação às palavras de ordem. Não existe significância independente das significações dominantes nem subjetivação independente de uma ordem estabelecida de sujeição pois ambas dependem da natureza e da transmissão das palavras de ordem em um campo social dado. Estamos diante de uma mecânica na linguagem que se insinua quando, segundo Deleuze e Guattari, o agenciamento coletivo impessoal exige e determina um trabalho de individuação do enunciado e da subjetivação da enunciação, de onde partimos para pensar em uma maquinaria comunicativa operada mediante uma linguagem movida por uma potência de variação contínua.

Desse modo, apontam para uma abordagem política da linguagem pelo coletivo - infrapessoal - em vez de pelo indivíduo - pessoal, colocando relevo na potência do obscurescimento da nitidez e da fixidez discursivas ao destacarem as variáveis de expressão que são imanentes à língua e que a colocam em relação com o Fora. 
Defendem, então, como estratégia política, tomar a linguagem como uma pragmática, como performance operada no entre das formas linguísticas que fazem dissonantes significado e significante, pois a pragmática para eles, não recorre simplesmente às circunstâncias externas; ela destaca as variáveis de expressão ou de enunciação que são, para a língua, razões internas suficientes para não se fechar sobre si mesma.

Assim, há sempre um agenciamento de enunciação molecular que não é dado pela consciência, bem como não depende apenas das determinações sociais aparentes, reunindo vários regimes de signos heterogêneos. Glossolalia, dizem eles, uma espécie de agenciamento do inconsciente, que seleciona vozes sussurrantes, convocando tribos e idiomas secretos.

Tal secretamento remete ao que não é dado na informação; remete ao silêncio, ao indizível que perturba a glosa, a explicação. Remete a nomadismo e não a território, permitindo que esse se fluidifique, aspecto essencial de qualquer trabalho político.

\section{Entre um Território Imperial de Soldados e um Nomadismo Bárbaro de Guerreiros High-Tech}

Deleuze e Guattari (1997) analisam as relações que caracterizam aquilo que definem como Aparelho de Estado e como Máquina de Guerra, para pensar os modos de estruturação e de mobilidade social.

Neste trabalho, os autores discorrem a respeito da coexistência dos dois, aparelho e máquina, dizendo que a guerra não está incluída no aparelho de Estado por vir de outra parte: trata-se de multiplicidade pura e sem medida, irrupção do efêmero e potência da metamorfose. A máquina de guerra refere-se ao secretamento do qual falamos, subverte as métricas e enaltece a força do segredo contra o público. Viver as coisas em relações de devir, dizem Deleuze e Guattari.

No Estado as peças são codificadas, têm natureza interior ou propriedades intrínsecas, de onde decorrem seus movimentos, suas posições, seus afrontamentos. Na máquina de guerra as peças têm função anônima, coletiva ou de terceira pessoa; são elementos de um agenciamento maquínico não subjetivado, sem propriedades intrínsecas, porém apenas de situação.

As relações são muito diferentes no aparelho de Estado e na máquina de guerra: no primeiro, as relações são biunívocas entre si e com as do adversário; suas funções são estruturais. Na máquina de guerra há apenas um meio de exterioridade, ou relações extrínsecas nebulosas que desempenham funções de inserção ou de situação como margear, cercar, arrebentar. Um guerreiro sozinho pode aniquilar toda uma constelação, enquanto soldados não podem: requerem um exército.

Esses, os soldados, pertencem ao aparelho de Estado. Sua missão é institucionalizar, regrar, codificar, distribuir-se num espaço fechado, no espaço estriado do Estado. Enquanto na máquina de guerra, trava-se uma luta sem linha de combate; é pura estratégia; distribuir-se num espaço aberto, preservar 
a possibilidade de surgir em qualquer ponto. Assim, o movimento já não vai de um ponto a outro mas torna-se perpétuo, sem alvo nem destino, sem partida nem chegada; constitui espaço liso.

Os guerreiros, em vez de afrontar o Estado, percorrem o Nomos; fazendo do Fora um território no espaço. Nômades, não se preocupam com ocupação de territórios e sim com desterritorialização através da ruptura interna de seu território, renunciando a si próprio. O guerreiro é excêntrico, louco e pecador: um traidor.

Assim, os elementos que compõem uma máquina de guerra são o segredo, a velocidade e o afeto, aqui considerado enquanto dimensão que rompe com qualquer interioridade subjetiva: trata-se do que se passa entre os corpos no meio social. Trata-se de alianças que resistem aos territórios e às codificações, por comporem um tecido de relações imanentes.

Dizem Deleuze e Guattari (1997, p. 21):

Não cabe dizer que a disciplina é o próprio da máquina de guerra: a disciplina torna-se característica obrigatória dos Exércitos quando o Estado se apodera deles; mas a máquina de guerra responde a outras regras, das quais não dizemos, por certo, que são melhores, porém que animam uma indisciplina fundamental do guerreiro, um questionamento da hierarquia, uma chantagem perpétua de abandono e traição, um sentido de honra muito suscetível, e que contraria, ainda uma vez, a formação do Estado.

Retomando nossa interrogação inicial a respeito das possibilidades de resistência aos movimentos de tradução da heterogeneidade expressiva pela codificação digital na Sociedade de Informação, problematizamos alguns aspectos que nos parecem pertinentes com o intuito de pensarmos para além da aparente obviedade de que as redes informacionais promovem a democracia e a diferença.

Concordamos com Haraway que a transgressão nas fronteiras humanosmáquinas favorecem fissuras em blocos identitários por remeterem a uma zona infrapessoal de forças que dão existência às coisas. Assim, não resta dúvidas de que as Novas Tecnologias se oferecem como potentes meios para o engendramento do novo, não exatamente porque favorecem uma conexão informativa em escala global entre as pessoas, já que isso, por si só, não garante que tal conectividade produza rupturas, mas porque instaura encontros entre elementos de naturezas diferentes perturbando as identidades.

Nossa suspeita recai sobre a busca por (in)formação "total”, característica da Sociedade de Informação. Afinal, será tácito que "dizer tudo" em velocidade cada vez mais assombrosa favorece os processos de vida e de criação? Não será no indizível, numa espécie de (out)formação que residem as forças guerreiras capazes de conjurar a formação de um aparelho de Estado no universo das Novas Tecnologias? Quais são os atos interiores às falas que se produzem e reproduzem nos ambientes informatizados, uma vez que conforme apontamos anteriormente, 
há uma subordinação da informação e da comunicação, bem como da significância e da subjetivação às palavras de ordem? Como pensar a cidadania em suas implicações no que se refere à relação entre público e privado?

Não seria esse um trabalho político a empreender na Sociedade de Informação: subverter a noção de público e de publicização ligada a uma incitação à comunicabilidade que marca nossa Era, de maneira a constituir uma maquinaria comunicativa que opera muito mais por secretamento?

Parece-nos que sim. Desse modo, um trabalho político em tempos hightech passa pela ativação de uma heterogeneidade expressiva no universo tecnológico acionada por uma (in)disciplina do a-gramatical. Passa pela perturbação do significado e do significante, pela comunicação de signos e pela fusão da imaginação com a realidade material, aspectos esses já presentes nas posições de Haraway quando enfatiza as potências de uma linguagem heteroglóssica na cultura tecnológica pela contestação dos dualismos que a hibridicidade humanos-máquinas comporta.

Tal política implica um agenciamento de coletivos pautados na diferença e não na identidade, no princípio da minoria e não da maioria, pois não se trata de obter quantidade de indivíduos que se juntam por compartilharem informações, mas por sincronia de individuações, de diferenciações que possibilitem uma espécie de comunhão por uma resistência às codificações.

Uma política em tempos de Alta Tecnologia convoca a existência de Ciborgues/Guerreiros High-Tech que em bandos subvertam o trabalho de Soldados em seus exércitos, os quais são responsáveis pela garantia de um território imperial tecnológico. Guerreiros que esperam permanecer em trajeto porque nisso reside o porvir, travessia inelutável para que se opere uma micromaquinaria comunicativa nos meandros da megamáquina informacional.

\section{REFERÊNCIAS}

CASTELS, M. A sociedade em rede. São Paulo: Paz e Terra, 2000.

DELEUZE, G. Foucault. São Paulo: Brasiliense, 1988.

DELEUZE, G.; GUATTARI, F. Mil Platôs: capitalismo e esquizofrenia. Rio de Janeiro: Editora 34, 1995. v. 2.

1997. v. 5.

. Mil Platôs: capitalismo e esquizofrenia. Rio de Janeiro: Editora 34,

HARAWAY, D. Manifesto Ciborgue: ciência, tecnologia e feminismo-socialista no final do século XX. In: SILVA, T. T. da (Org.). Antropologia do Ciborgue: as vertigens do pós-humano. Belo Horizonte: Autêntica, 2000. p. 39-129.

Recebido em: maio de 2008

Aceito em: dezembro de 2008 